\title{
Bilgi Teknolojisinin Yapısal ve Yönetsel Açılardan Bilgi-Belge Merkezlerine Getirdiği Yenilikler*
}

\author{
Structural and Managerial Innovations Provided to \\ Information and Documentation Centers by Information \\ Technology
}

Mesut KURULGAN**

\begin{abstract}
Öz
Bu çalışma, 1990'lı yıllardan itibaren yaygın olarak kullanılmaya başlayan bilgi teknolojisinin, yapısal ve yönetsel açılardan bilgi-belge merkezlerine getirdiği yenilikleri ele almaktadır. Bu yenilikler, bilgi kayıt ortamları, bina, iş akışı, işgören ve yönetici, işbirliği, standartlaşma, hizmetler, kütüphane/bilgi belge merkezi kavramı, örgüt kültürü, yönetim ve organizasyon yapısı, paydaşlar açısından irdelenmiştir. Çalışmada ayrıca, bilgi teknolojisinin bilgi-belge merkezlerinde etkin kullanımını sağlamak için alınması gereken önlemlere ilişkin önerilerde bulunulmuştur.
\end{abstract}

Anahtar s zc kler: Bilgi teknolojisi, Kütüphane otomasyonu, Bilgi sistemleri, Yeniden yapılanma.

\begin{abstract}
This research is concerned with structural and managerial innovations in information and documentation centers brought by information technologies that have found widespread use since the 1990's. The mentioned innovations have been examined from the aspects of information recording media, buildings, work flow, worker and manager, cooperation, standardization, services, the concept of library/information and documentation center, organizational culture, structure of management and organization, and stakeholder perspectives. The study also presents suggestions about arrangements to ensure
\end{abstract}

\footnotetext{
`Bu makale, ÜNAK'05 “Bilgi Hizmetlerinin Organizasyonu ve Pazarlanması” (22-24 Eylül 2005) toplantısında sunulan bildirinin gözden geçirilmiş ve genişletilmiş biçimidir.

**Uzman; Anadolu Üniversitesi Avrupa Birliği Araştırma Uygulama ve Dokümantasyon Merkezi Yunus Emre Kampusu 26470 Eskişehir (mkurulgan@anadolu.edu.tr).
} 
effective use of information technologies in information and documentation centers in Turkey.

Keywords: Information technology, Library automation, Information systems, Restructuring.

\section{Giriş}

Fikir ve sermaye yoğun bir örgüt türü olan kütüphane/bilgi-belge merkezleri, tıpkı diğer örgütler gibi iç ve dış çevre etmenlerinin etkisi altındadır. İş gören, donanım, teknoloji, bilgi, para, kullanıcı, bina, hizmet, yönetim gibi dinamikler genellikle "iç etmenler" olarak ifade edilirler. Buna karşılık, örgütün içinde yer aldığı dış çevre ile onun ekonomik, politik, coğrafik, teknolojik ve tarihsel yapısı ve özellikleri gibi ögeler "dış etmenler"i oluşturmaktadır. i̇ç etmenler, örgütsel faaliyetlerin başlatılması ve sürdürülmesi için vazgeçilmez olan, herhangi biri eksik ya da yetersiz olduğunda faaliyetleri belirgin bir biçimde aksatan; örgütün iç yapısında ve işleyişinde her an varlığını hissettiren dinamiklerdir. Bu bağlamda dış etmenlere göre daha somut oldukları ve denetlenmelerinin de daha kolay olduğu söylenebilir (Yontar, 1995, ss. xi-xii).

Literatürde kısaca "bilgi teknolojisi/bilişim teknolojisi" (BT) olarak adlandırılan bilgisayar ve telekomünikasyon (uziletişim) teknolojilerinin bilgi hizmetlerinde etkin kullanımı, hatta onu yönlendirmeye ve biçimlendirmeye başlaması, bilgi-belge merkezi faaliyetlerinin yürütülmesinde çeşitli olanaklar sunması yanında, var olan faaliyetlerin pek çoğunun yeniden gözden geçirilmesine neden olmaktadır. BT'nin, bilginin örgütlenmesi ve kullanıcılara ulaştırılmasından, yönetim işlevlerine kadar her alanda etkin olması, bilgibelge merkezi yatırımlarının daha geniş bir çerçevede ele alınmasına neden olmakta, bu durum da kıt kaynakların etkin kullanılmasının önemini daha da artırmaktadır (Kurulgan, 2005, s. 42). Bu bağlamda bilgi-belge merkezlerinin yapısal ve yönetsel açılardan "bilgi kayıt ortamları, bina, iş akışı, işgören ve yönetici, işbirliği, standartlaşma, hizmetler, kütüphane/bilgi-belge merkezi kavramı, örgüt kültürü, yönetim ve organizasyon yapısı, paydaşlar" gibi konularda BT'nin getirdiği kökten değişime koşut bir yeniden yapılanma sürecine girdikleri söylenebilir. Önemini vurgulamak gerekirse; burada yapılan iş bir "yeniden örgütlenme" (re-organization) değil, bir "süreçlerin yeniden düzenlenmesi" (re-engineering), bir "yenileşme" (modernization) değil, başlı başına bir "dönüşüm" (transformation) sürecidir (Yurdadoğ, 1997, s. 73).

Bu çalışmada, BT'nin bilgi-belge merkezleri üzerinde yarattığı dönüşümü yapısal ve yönetsel açılardan irdelemek amacıyla literatürden elde edilen bilgiler değerlendirilmektedir. Bu bağlamda merkezlerde yaşanan yenilikler; "bilgi kayıt ortamları", "bina”, "iş akışı", "işgören ve yönetici", "işbirliği-kaynak 
paylaşımı-standartlaşma", "hizmetler", "kütüphane kavramı", "örgüt kültürü”, "yönetim-organizasyon yapısı" ve "paydaşlar" olmak üzere on başlık altında toplanmıştır.

\section{Bilgi Teknolojisinin Bilgi Kayıt Ortamları Açısından Getirdiği Yenilikler}

Bilginin kayıttı olduğu ortam tarihsel gelişim içinde farklııklar göstermektedir. $\mathrm{Bu}$ gelişme taştan kil tabletlerine, papirüsten parşömene; parşömen destelerinden el yazması kitaplara; basılı kâğıttan günümüzdeki manyetik, optik ve etkileşimli çoklu araçlara kadar devam etmiştir (Alakuş, 2005).

Dünyamız, Gutenberg'in buluşu olan matbaayla yarattığı ilk bilgi-belge patlamasından sonra günümüz bilgi toplumunda ikinci bir bilgi-belge patlaması dönemi yaşamaktadır. Bu ikinci olayın en önemli nedenini ise, BT'de yaşanan gelişmeler oluşturmaktadır (Kurulgan, 2004, s. 41). Örneğin, 2002'de üretilen yeni bilgi miktarı verilerine bakıldığı zaman, ikinci bilgi-belge patlaması döneminin rakamsal büyüklüğünün intişamı görülebilmektedir. Bu verilere göre; 2002 yılında üretilen yeni bilgi miktarı 5 exabyte $=5 \times 10^{18}$ byte'dır ve 37.000 yeni Kongre Kütüphanesi dermesine karşılık gelmektedir. Ayrıca web üzerinde bulunan ve arama motorlarının dizinlerinde yer alan belgelerin bulunduğu kısımda (yüzey web) 10 milyar belge (167 terabyte $=167 \times 10^{12}$ byte) bulunmaktadır. Web üzerinde bulunan ve arama motorlarının dizinlerinde yer almayan belgelerin bulunduğu kısımda (derin web) ise 550 milyar belge (91857 terabyte) bulunmaktadır (Sever ve Tonta, 2005). Kaliforniya Berkeley Üniversitesi'nden "School of Information Management and Systems" profesörlerinden Peter Lyman ve Hai Varian'ın yönetimindeki bir ekip tarafından gerçekleştirilen araştırmaya göre; dünya çapındaki bilgi üretimi yılda $\% 30$ artmaktadır (Turk.internet.com Haber Merkezi, 2004).

Yaşanan bu büyük bilgi patlaması karşısında, merkezlerin derme geliştirme ilkelerini yeniden gözden geçirmelerini ve BT olanaklarından yararlanmalarını gerektirmektedir. Bu durumda merkezler geleneksel "just-in-case (gereksinim duyulursa diye/önlem olarak)" görüşü yerine "just-in-time (gereksinim duyulduğu anda)" ilkesini benimsemekte ve bilgi-belgeye erişim mi, yoksa edinim mi tartışmalarına girebilmektedirler. Bu konuda daha radikal düşünenler, derme oluşturma yerine dışarıdaki dermelere erişmeyi daha ekonomik bulabileceklerdir (Yurdadoğ, 1997, s. 76).

\section{Bilgi Teknolojisinin Bina (Mekân) Açısından Getirdiği Yenilikler}

BT, mesafeleri ortadan kaldırmak suretiyle geleneksel bilgi-belge merkezi binalarına olan bakış açısını da değiştirmiştir. BT ile elektronik bilgi-belge 
merkezleri, çevredeki kütüphaneden daha yakın bir konumdadır. İnternet aracılığıyla bu merkezlere evlerden ya da bürolardan erişim sağlanabilmektedir. Bu süreç kullanıcının geleneksel kütüphanecilik anlayışındaki aracılardan kurtulmasına olanak veren bir etki yaratmaktadır (Hooper, 2001, s. 72). BT'nin sağladığı olanaklar, bilgi-belge merkezlerinin yönetimi ve işleyişi açısından bulunulan yere bağımlıı̆̆ını da azaltmaktadır. Yönetim, planlama, hizmetlerin yönlendirilmesi ve yerine getirilmesi artık farklı yerlerde yapılabilmektedir. Bundan dolayı post-modern dünyada merkez tek bir yer değil, aksine her yerdir (Bozkurt, 2000, ss. 94-95).

BT kullanımı ayrıca, bilgi-belge merkezi binalarının geleneksel önemini yitirmesine neden olmakta ve kağıda dayalı belgelerin depolama sorunlarını en aza indirmektedir. Çarpıcı bir örnek vermek gerekirse, Kaliforniya Üniversitesinin dokuz kampusta bulunan kütüphanelerine eklenen kağıda dayalı belgeler için, her yıl 19.3 km'lik raf ilavesi gerekmektedir (Buckland, 2002). Kaliforniya Üniversitesi kütüphanecileri, belgeleri, her ne kadar ayıklama işlemine tabi tutsa dahi, kütüphane mekânının belirli bir süre sonra kullanılamaz duruma gelmesine engel olamayacaklardır. Bu ve benzeri durumlarda kütüphanecilerin en büyük yardımcısı olan BT, mekân daralmasını engelleme konusunda, onlara kağıda dayalı belgelerin hiç değilse bir kısmını elektronik ortama aktararak büyük depoların, uzun raf alanlarının azaltııması olanağını sunmaktadır (Yurdadoğ, 1997, ss. 75-76).

\section{Bilgi Teknolojisinin İş Akışı Açısından Getirdiği Yenilikler}

BT kullanımı sonucu geleneksel bilgi-belge merkezlerindeki iş akışı büyük ölçüde değişmiştir. Örneğin; geleneksel kütüphane sisteminde belgenin sağlanması sırasında yapılan işlemlerin bir bölümü, kataloglama-sınıflama sürecinde yinelenmekteydi. Ancak BT'ye dayalı kütüphane sisteminde, belge sağlama sürecindeki dokümana ilişkin bibliyografik kimliklerin oluşturulması gibi işlemlerin, kataloglama-sınıflama sürecinde de tekrarı engellenmiştir. Bu bir bakıma sağlama sürecinde, daha belge kütüphaneye kazandırılmadan önce yayıncı ve kitap kataloglarından yararlanılarak ve/veya belgenin kütüphaneye alınmasını isteyen kişi veya ekibin bilgisine başvurularak, belgenin kataloglama işlemlerinin yapılması anlamına gelmektedir (Yalvaç, 1994, ss. 53-54). Örneğin, Functional Requirements for Bibliographic Records $=$ FRBR (Bibliyografik Kayıtlar İçin İşlevsel Gerekler) gibi yöntemlerle basım tarihi ve türü farklı ancak içerikleri aynı olan dokümanlara birden fazla kataloglama işlemlerinin yapılması önlenebilmektedir (Özel, 2005).

Gelişen teknoloji değişik yöntemler kullanılarak elektronik bilgi ve belge sağlama hizmetleri verilmesini mümkün kılmaktadır. Bu hizmetlerin bir kısmı "itme" (push) teknolojileri kullanılarak verilmektedir. İçindekiler sayfası ve 
seçmeli bilgi duyurusu hizmetleri buna örnek olabilir. Kullanıcıların ilgi alanları belirlendikten sonra, belirli aralıklarla onların ilgi alanlarında yayımlanan dergilerin içindekiler sayfaları, ya da dermeye yeni eklenen elektronik bilgi kaynaklarından tanımlanmış ilgi alanlarına uyan bibliyografik künyeler veya bilgi kaynaklarının tam metinleri kullanıcıların e-posta adreslerine gönderilebilir. Çoğu sayısal kütüphaneler bilgi hizmeti sunarken hem "itme" hem de "çekme" (pull) teknolojilerini kullanmaktadır. Başka bir deyişle, kullanıcılarla etkileşim kurulmakta, örneğin onların hangi konuda belgelere gereksinim duydukları çevrimiçi kataloglar aracılığıyla belirlenmekte ve bu belgelerin elektronik belge sağlama sistemine otomatik olarak aktarılması sağlanmaktadır. Basılı kaynakların sayısallaştııımasıyla oluşturulan ve elektronik bilgi kaynaklarını da içeren elektronik rezerv dermeleri de çekme teknolojisine örnek olarak verilebilir (Tonta, 2002).

Örneklerden de anlaşılacağı üzere; BT kullanımı sonucu bilgi-belge merkezlerindeki geleneksel iş akışı değişmiş ve hizmetlerin daha kısa sürede, sıfır hatayla gerçekleştirilmesi sağlanmıştır.

\section{Bilgi Teknolojisinin İşgören ve Yönetici Açısından Getirdiği Yenilikler}

BT, bilgi-belge merkezlerindeki tekdüze işlerin yapılması görevini üstlenerek, işgören ve yöneticinin işine ayırdığı zamanı önemli ölçüde azaltmıştır. Örneğin, kütüphanelerde geleneksel olarak hazırlanan sipariş kataloğu, demirbaş listeleri, katalog kartlarının çoğaltılması, ödünç verme ve dolaşımda olan belgelerin izlenmesi, basılı kataloglardan kitap, süreli yayın gibi dokümanların taranması, yönetim kararlarında kullanılan rapor ve istatistiklerin tutulması, işgörenin denetlenmesi gibi işlemler BT ile daha kısa sürede ve sıfır hatayla gerçekleştirilmektedir. Böylece mevcut işgörenle daha çok iş yapılmakta, işgören zamanı ve sayısından tasarruf sağlanmaktadır (Kurulgan, 2004, s. 85).

BT işgören sayısındaki artışları engellemekle birlikte, işgören niteliğini de ön plana çıkarmaktadır. İleri teknoloji ürünü olan hassas ve karmaşık BT ürünlerinin kullanımı ve yönetilmesi, bilgi-belge merkezleri işgöreninin belirli niteliklere sahip olmasını gerektirmektedir. İşgören, yeterli bilgi-belge yönetimi/kütüphanecilik bilgisinin yanında; bilgisayar kullanımı, veri tabanları ve bilgisayar ağları gibi alanlarda bilgi sahibi olmalıdır. Özellikle İnternet kullanımı, bilgi otoyolunda ve web sayfalarında kaybolmadan aradığını bulabilmeyi bekleyen kullanıcıya rehberlik için görev tanımları yeniden yazılması, işgörenin bilgi-beceri açısından desteklenmesini zorunlu kılmaktadır (Lakos ve Gray, 2000). O halde önemli olan, işgörenin geleneksel işleri devam ettirme hevesi yerine, yeni koşulların zorunlu kıldığı gereksinimleri karşılayacak nitelikleri kazanması için kurs, seminer, özel çabalar veya formal eğitimle kendini 
yenileyebilmesidir (Yurdadoğ, 1997, s. 77). İşgören kendini yenileme sürecinde, örneğin İnternet üzerinden eğitim kurslarına katılarak, sanal bir biçimde bilgi ve becerisini geliştirebilmektedir (Steele ve Guha, 1999).

BT ve gelişen yönetim teknikleri, kütüphane işgöreninin yanı sıra yöneticilerin de strateji geliştirme, proje yönetimi, bütçe yönetimi, sorun çözme, liderlik, pazarlama, iletişim, takım yönetimi, esneklik, işgören eğitimi, danışmanlık, ağ bilgisi ve İnternet, BT'yi etkin kullanma bilgi ve becerisi gibi niteliklerini önemli ölçüde geliştirmiştir (Bahşişoğlu ve Çömlekçi, 2002).

\section{Bilgi Teknolojisinin İşbirliği, Kaynak Paylaşımı ve Standartlaşma Açısından Getirdiği Yenilikler}

Bilgi-belge yönetimi mesleğinin temelinde yatan ve bilgi-belge yöneticilerinin de en büyük özlemlerinden biri olan işbirliği, kaynak paylaşımı ve standartlaşma ilkesi ile bilgi kaynaklarını daha etkin kullanma ve kaynak savurganlığını önleme konusundaki çalışmalar, geleneksel sisteme göre daha büyük hız ve kullanım kolaylığı kazanmıştır. Bunun en önemli nedeni, otomasyonun temel amaçlarından birisinin standartlaşmaya gidilerek evrensel bilginin ulusal ve uluslararası boyutta değişim-erişimini hızlandırmak ve kolaylaştırmak olmasıdır. Standartlaşma; bilgi-belge merkezlerinin donanım, yazılım, dokümantasyon ürünleri ve zihinsel işlemlerini etkileyerek, kullanılan yöntem ve teknikleri iyileştirmekte, basitleştirmekte ve uyumlaştırmaktadır. Bundan dolayı, merkez işlemleri hız kazanmakta, maliyetler azalmakta ve gecikmeler önlenmektedir (Yalvaç, 1994, ss. 55-56).

Günümüz bilgi-belge merkezlerinin tümünde kullanılmakta olan bilgi ve iletişim teknolojileri merkezlerin sadece kendi dermelerinden yararlanma sınırlamasından kurtulmalarını da beraberinde getirmektedir. Geleneksel olarak yürütülen merkezler arasındaki ödünç verme ve işbirliği çalışmaları daha da genişlemekte ve hızlanmaktadır. Bilgi merkezleri açısından bu durum, bireysellikten uzaklaşma ve bağlı bulunduğu sistemin bir parçası olma zorunluluğunu getirmektedir. Bu yüzden merkezler, kendi aralarında ağlar ve konsorsiyumlar kurarak çeşitli oluşumlar içinde ortak projeler geliştirmekte ve sorunlarını tartışarak etkin çözüm yolları aramaktadır (Anameriç ve Rukancı, 2004, ss. 336-337). Bunun en güncel örneği, ÜNAK ve OCLC'nin ortaklaşa yürüttükleri “Türkiye Üniversiteleri Toplu Katalog Projesi"dir (Çömlekçi, 2005).

\section{Bilgi Teknolojisinin Kullanıcıya Yönelik Hizmetler Açısından Getirdiği Yenilikler}

Geleneksel bilgi-belge merkezlerinde bir kitap veya dergiye sahip olmak, bu bilgi kaynağındaki bilgi içeriğine en az bir kullanıcı tarafından erişilmesini 
garantilemektedir. Merkezin kaynağa sahip olmadığı durumlarda, kullanıcılar bilgi kaynağını başka yerlerde aramak durumundadır. Ancak, ağ aracılığıyla erişilebilen bilgi kaynaklarında durum oldukça farklıdır. Bu tür kaynaklara web aracılığıyla erişim sağlamak, bu kaynakları merkez dermesinde bulundurmak kadar değerlidir.

Kütüphane hizmetlerinde BT kullanımı kütüphaneciye zaman kazandırarak, kullanıcı ile daha yakından ilgilenmesine, kullanıcı eğilimlerini, isteklerini ve sorunlarını saptamak suretiyle onlara daha etkin hizmet sunmak için önlem almaya yönelik çalışmalar yapmasına olanak sağlamaktadır. Bununla birlikte bilgi-belge merkezi, BT'den yararlanarak çok düşük maliyetle yakınındaki veya uzak yerleşim bölgelerindeki kullanıcılara yeni hizmetler sunabilmektedir (Yalvaç, 1994, s. 57).

BT aracılığıyla geliştirilen kütüphane tabanlı siteler, kullanıcılara bilginin örgütlenmesi ve karar verme gibi süreçlerdeki güçlükleri yenebilecek beceriyi kazandırmaktadır. Örneğin; sistem, kullanıcıların bilgiye erişim konusunda yetersiz kaldığı durumlarda, onlara danışmanlık hizmeti vererek, bilgiye ulaşamama kaygılarını ortadan kaldırmakta ve tercihlerini özelleştirmelerine fırsat tanımaktadır (Lakos ve Gray, 2000).

Bilindiği gibi geleneksel kütüphanelerde basılı olarak hazırlanan yeni yayın listelerinin bireysel bazda ilgili bölümlere gönderilmesinde önemli sorunlar yaşanmaktadır. Bu sorunu gidermek üzere oluşturulan ve bilgi-belge merkezi hizmetlerinin kişiselleştirilmesi olarak bilinen MyLibrary, MyUpdates hizmetini gündeme getirmiştir. Bu ürün, "Seçimli Bilgi Yayımı (SDI)" hizmetiyle araştırmacıların bilgi-belge merkezine yeni gelen kaynaklar hakkında bilgi sahibi olmalarını sağlamaktadır (Kohen, 2000).

\section{Bilgi Teknolojisinin Kütüphane/Bilgi-Belge Merkezi Kavramı Açısından Getirdiği Yenilikler}

Bilgi-belge yönetimi literatürü incelendiği zaman bilim insanları ve uygulamacılar tarafından, BT kullanımı sonucu ortaya çıkan sanal kütüphane, elektronik kütüphane, sayısal kütüphane, duvarsız kütüphane, kâğıtsız kütüphane, kablolu kütüphane, boyut değiştiren/esnek kütüphane, masaüstü kütüphane, çevrim-içi kütüphane, bilgi otoyolu gibi bilgi-belge merkezi terimlerine yönelik pek çok araştırma ve makale çalışmasının yapıldığı görülmektedir.

Günümüzde henüz deneme aşamasında olan sanal kütüphanelerde sanal gerçeklik teknolojisi kullanılmaktadır. Bu yeni yapının amacı, BT'nin sunduğu bütün olanaklardan yararlanarak, mekân ve zaman anlamında gerçek bir kütüphaneye gitmeden sanki gerçek bir kütüphaneye gitmiş gibi; kataloğun taranması, rafların arasında dolaşılması, istenilen bilgi kaynağı sayfalarının açııp okunması, ses kayıtlarının dinlenmesi gibi işlemlerin sanal ortamda yapılmasını sağlamaktır. 
Literatürde sanal kütüphane, elektronik kütüphane, masaüstü kütüphane, çevrim-içi kütüphane ve bilgi otoyolu terimlerinin zaman zaman birbirinin yerine kullanıldığı görülmektedir. Bunların yanı sıra, çok sık geçmemekle birlikte; duvarsız kütüphane, kâğıtsız kütüphane, kablolu kütüphane ve boyut değiştiren/esnek kütüphane (diffuse library) kavramları bulunmaktadır. Duvarsız kütüphane, kullanıcının (bina olarak) bilgi-belge merkezine gitme zorunluluğundan kurtularak uzaktan erişim sağlamasını ifade etmektedir. Kâğıtsız kütüphane terimi ise, dermesini basılı olmayan ya da kâğıt içermeyen kaynaklardan oluşturan merkezler için kullanılmaktadır. Yine az rastlanan bir başka terim de kablolu kütüphanedir. Kablolu kütüphane, gereksinim duyulan bilgilerin elde edilmesinde ve iletilmesinde kullanılan bilgisayar ağlarının rolü ön planda tutularak oluşturulmuş bir terimdir (Yurdadoğ, 1997, s. 75). Fizik biliminde yayınım (diffusion), molekül, atom, iyon ve elementlerin arasından çıkarak, birleşim olmaksızın moleküllerin içine girmesi olayıdır (Lougee, 2003). Örneklemek gerekirse, kullandığımız parfüm/losyonda bulunan koku molekülleri, hava moleküllerinin içine (diffuse) nüfuz eder, havadaki hareketleri sonucunda bir başkası tarafından fark edilir. Bu tepkime sırasında "koku molekülleri" "hava moleküllerinin" biçimini değiştirmemiş ancak kokusunu değiştirmiştir. Benzer bir biçimde kütüphane hizmetlerinin eğitim ve araştırma faaliyetlerinin içine nüfuz etmesi olayını gerçekleştiren kütüphane türü söz konusudur (Küçük, 2004, s.46). Bu tanımlamayı bilgi-belge merkezine uyarlamak gerekirse, merkezlerin akademik kurumların temel görevleriyle iç içe geçtiği, bilginin oluşturulması ve yayılması konusunda akademik kurumları oluşturan diğer ögelerle etkileşim halinde çalıştığı söylenebilir. Diffuse library adı verilen bu tür merkezler kendi benliklerini korurken, aynı zamanda akademik birimler arasında bir köprü hizmetini de görmektedir (Lougee, 2002). Temelde, geleneksel yerleşik, merkeziyetçi ve bina esaslı kütüphane yerine, ağa dayalı, dağıtık 7/24 bilgi hizmetlerinin örgütlendiği ve sunulduğu yeni bir paradigma öngörülmektedir. Kimi yazarlara göre bu, "aynı şarabın yeni şişe içinde sunulması", kimilerine göre ise kütüphane hizmetlerinin "boyut değiştirmesi” olarak yorumlanmaktadır. Denilmektedir ki, kütüphaneden ödünç alınan bilgi kaynaklarının sayısı, kütüphaneyi fiziksel olarak ziyaret eden kullanıcıların ve müracaat masasına yüz yüze iletilen soruların sayısı her geçen gün azalmakta, ağa dayalı hizmetlerin kullanımı artmakta ve önceleri sadece sağladıkları bilgi kaynaklarını düzenleyip kullanıcılarına sunan kütüphaneler, sayısallaştırma projeleriyle birlikte bilginin yeniden paketlenmesinde ve erişim modelinin oluşturulmasında işlevsel hale gelmekte ve kendisine yeni roller tanımlamaktadır (Küçük, 2004, ss. 46-47).

Bütün bu tanımlardan anlaşıldığı üzere, bilgi-belge merkezlerine hangi adlar verilirse verilsin, hepsinin de ortak noktası "işlevlerini elektronik ortam- 
da gerçekleştiriyor” olmalarıdır. Çalışmada kavram kargaşasını önlemek için, gerek dermenin büyüklüğü ve gerekse konu uzmanlarının sayı ve nitelikleri açısından dünyanın en büyük kütüphanelerinden biri olan Amerikan Kongre Kütüphanesi'nin kataloğundan 5 Haziran 2002 tarihinde, "virtual library", "digital library" gibi konu başlıkları çevrimiçi olarak sorgulanmış ve anılan terimlerden "electronic library" sözcüklerine gönderme yapıldığı belirlenmiştir. Bu tür kütüphane terimleri arasında bazı özel nitelik farklılıkları bulunmasına rağmen, bütün terimler "elektronik kütüphane" ortak çatısı altında toplanmıştır (Kurulgan, 2004, ss. 91-92).

Kapsamlı bir tanımlama yapmak gerekirse, "elektronik kütüphane, elektronik formdaki sosyal, ekonomik, kültürel ve entelektüel çalışmaların farklı kopyalama ve düzenleme stratejileri kullanılarak oluşturulan metin, görüntü, harita, ses, ticari kataloglar, bilimsel, ticari işletme ve kamu yönetimi veri kümelerinin, çeşitli bilgi-belge merkezleriyle etkin iletişim ağı kurulması suretiyle, bir bütünlük içinde uzun dönem erişim sağlanmasında ortak bir sorumluluğa ve haftanın 7 günü 24 saat uzaktan erişim olanaklarına sahip olan bilgi-belge merkezi" biçiminde tanımlanabilir (Tonta, 1998). Tanımdan da anlaşılabileceği gibi elektronik kütüphane, bilgi toplumu felsefesini yansıtan ve geçmişi geleceğe bağlayan kültürel bir varlık olarak karşımıza çıkmaktadır.

\section{Bilgi Teknolojisinin Örgüt Kültürüne Olumlu Etkisi}

Örgüt kültürü; baskın ve paylaşılan değerlerden oluşan, çalışanlara sembolik anlamlarla yansıyan, örgüt içinde anlatılan öykü, inanç ve sloganlardan oluşan bir yapıyı ifade etmektedir (Berberoğlu, 2002, s. 252).

BT'nin örgüt kültürü ve iklimi üzerine etkileri konusunda uygulamaya dönük çeşitli araştırmalar yapılmıştır. 2004 yılında yapılan, BT'nin üniversite kütüphanelerindeki yönetim işlevleri üzerine etkilerini belirlemeye yönelik bir araştırmada (Kurulgan, 2004, s. 234), ülkemizdeki üniversite kütüphanelerinin \%75.5'inin "BT, arzulanan örgütsel iklim ve uygun çalışma ortamının hazırlanmasında etkin rol oynamıştır" fikrine katıldıkları belirtilmektedir. İletişim sektöründe faaliyet gösteren işletmeleri inceleyen bir başka çalışmada "araştırmanın uygulandığı şirketler grubunda, BT, hizmet içi eğitim ve üst yönetimin işgöreni teşvik etme, destek verme ve ödüllendirmedeki bilinçli yaklaşımı sayesinde çalışanlar, BT uygulamalarına bağlı olarak yaşadıkları değişimi, oldukça olumlu olarak algılamaktadırlar" (Dikmen ve Yahyagil, 2001, s. 902) saptaması yapılmaktadır.

Araştırmalara ilişkin bulgular örgüt kültürünün $B T^{\prime}$ 'den olumlu yönde etkilendiğini göstermektedir. Örgütlerin sürekli olarak müşteriye en iyi 
hizmet/ürünü sunma uğraşı; yapısal ve yönetsel ögelerde değişim ve uyum sürecine girmelerine neden olmaktadır. Böylece BT; amaç, vizyon, yapı, strateji, ödül sistemleri, eğitim programları, değerler ve örgütsel yaşama ilişkin yeni kuralları ile kültürel alanda büyük değişim ve gelişmelere neden olmaktadır. Bu gelişmelerden biri, BT'nin bütün örgüt çalışanlarına zamanlı ve doğru bilgiler sağlayarak bireysel düzeyde işgöreni özgürleştirmesi, kendini kanıtlama ve gerçekleştirmesine olanak tanımasıdır. Dolayısıyla, işgören sadece emirleri uygulayan birey olmaktan çıkarak, edindiği bilgilerle kendi işiyle ilgili kararlarda söz sahibi olabilmektedir.

İkinci önemli husus, BT aracılığıyla işgörenin eğitilmesi konusudur. BT'nin bilgi-belge merkezlerine girmesiyle birlikte, daha önce işlerini geleneksel yöntemlerle yürüten ve teknolojiyi sınırlı olarak kullanan çalışanlar değişim ve gelişmelere karşı direnç göstermektedir. Örgütlerde doğal karşılanması gereken bu direnç, işin gereklerinin teknolojiye dayalı olarak gelişmesi karşısında, işgörenin nitelik açısından bu gerekleri karşılayamaz duruma gelmesinden kaynaklanmaktadır. Bu olumsuz durumu ortadan kaldırabilmek için yöneticilerin, eğitim programlarına ağırlık vererek, işin gerekleriyle işgörenin niteliklerini birbirine yaklaştırmaları gerekmektedir (Kurulgan, 2004, ss. 206-207). Elektronik ortamda sunulan eğitim merkezleri sayesinde; işe alıştırma ve eğitimler için kaybedilen zaman maliyeti düşürülmekte ve bilgiye erişim her zaman etkin bir biçimde sağlanmaktadır. Örneğin, yurt dışı eğitim programlarına katılmış olan işgören, elektronik bilgi paylaşma platformları aracılığıyla, aldığı eğitimle ilgili dokümanları ve bilgileri bütün çalışanlara sunma olanağını bulabilmektedir (Kurulgan, 2004, s. 201).

\section{Bilgi Teknolojisinin Yönetim ve Organizasyon Yapısı Açısından Getirdiği Yenilikler}

Sanayi toplumundan bilgi toplumuna geçiş sürecinde, BT; diğer örgütlerde olduğu gibi bilgi-belge merkezlerinin de organizasyon ve işleyiş yapısını, yönetim ve liderlik anlayışını, çalışma ilkelerini ve biçimlerini, bireysel davranışları değiştirmiştir (Bayrak, 2003, s. 171). BT'nin bu alandaki etkileri altı başlık halinde incelenebilir:

\section{Organizasyon Yapısı Üzerine Etkileri}

BT'nin organizasyon yapısı üzerine etkileri, özellikle merkezi ve yerel (merkezi olmayan) yönetim üzerine olmuştur (Ülgen, 1990, s. 213). Bu konuda çalışma yapan yazarların bir kısmı; BT'nin organizasyon yapısında merkezileşme eğilimini artırdığını, diğerleri ise, tersine yerelleşme eğilimine yol açtığını ileri sürmüşlerdir. Simon, bilgisayar ortamındaki karar işlevlerindeki erişim gücü nedeniyle merkezileşmenin ortaya çıktığını belirtmiş ve Whisler da bu durumu BT'nin karar alma gücünü yukarı kademelere doğru 
kaydırmasıyla ilişkilendirmiştir. BT kullanımının yerelleşme uygulamalarını artıracağı görüşünde ise, teknoloji kullanımının aşağıya dönük bilgi akışını kolaylaştırmasıyla işgörenin yönetim ve karar alma faaliyetlerine katılımını artıracağına dikkat çekilmiştir (Bayrak, 2003, s. 171). 2004 yılında, BT'nin üniversite kütüphanelerindeki yönetim işlevleri üzerine etkilerini belirlemeye yönelik yapılan araştırma (Kurulgan, 2004, s. 229) bulguları da (yöneticilerin, kısmen katılıyorum görüşünde olanlar da dahil olmak üzere, \%85.7'si, yönetim basamaklarında yerelleşmeye doğru bir gidiş olmuştur yanıtını vermiştir) bu görüşü desteklemektedir. Bu bağlamda, bürokratik-basamaksal organizasyon yapıları, esnek üretim ve uzmanlaşmaya olanak veren yapılara dönüşecek ve özellikle post-modern yapılar biçiminde adlandırılabilecek organizasyon yapıları olarak şebeke organizasyonlar, yalın organizasyonlar, stratejik birlikler, organik organizasyonlar, bilgi tabanlı organizasyonlar, adhokratik (geçici) organizasyonlar, matriks organizasyonlar, sosyo-teknik organizasyonlar, hibrid organizasyonlar, hücresel organizasyonlar, öğrenen organizasyonlar ve sanal organizasyonlar yaygınlık kazanacaktır (Bayrak, 2003, ss. 171-172; Ögüt, 2003, ss. 81-107).

Peters-Waterman ve Senge konuya bir başka açıdan yaklaşmaktadırlar. Yazarlara göre; "bilgisayarların karakteri karar verenleri de etkilemiştir. Merkezi sistem (mainframe) bilgisayarlar yaygınken, yönetim makamları karar alma sürecinde merkeziyetçiliği desteklemiş, kişisel bilgisayarlar ve iletişim ağlarının gelişmesi ise karar alma sürecini yerelleştirmeye başlamıştır. Bilişim teknolojisi, geleneksel örgütsel yapılarını modası geçmiş hale getirirken katılımcı modellerin de yaygınlaşmasını destekleyecektir. Bugün başarılı olan ve gelişmiş teknolojileri kullanan örgütlerin yönetimde katılımcı modelleri uygulaması, bu eğilimin bir yansıması gibi algılanmaktadır" (Marchant ve England, 1989, s. 477).

\section{Otorite ve Kontrol Üzerindeki Etkileri}

Yönetsel güç kaynaklarından biri olan otorite, yasal güç ile eş anlamda kullanılmaktadır. Kontrol, kişisel etkileşim süreci olarak tanımlandığında örgüt içinde bireyin astlarını, üstlerini ya da meslektaşlarını etkilemesi anlamına gelmektedir. BT, örgütlerde daha önce bireyler tarafından yapılan kontrol etkinliklerini üstlenerek hata yapma olasılığını en aza indirmektedir. BT kullanımı ile birlikte, örgütlerde olası bir başka değişim de yetki ve kontrol çizgisinin belirsizleşmesi beklentisidir. Bunun temel nedeni ise, daha önceleri bölüm düzeyinde gerçekleştirilen kontrollerin günümüzde BT aracılığıyla yapılmasıdır. Bu durum bölüm bazında yetki-kontrol arasındaki açıklığın kaybolmasına neden olmaktadır (Öğüt, 2003, s. 75).

Sonuçta, BT otoritenin yönetim merkezinden uzaklaştırılarak, daha alt 
düzeye göçerilmesine, çalışanların güçlendirilmesi (empowerment), etkinlik ve kalitenin artırımasında ekip çalışmasına ve katılım yoluyla farklı yapısal dönüşüme doğru gidişi sağlamıştır (Bayrak, 2003, s. 172).

\section{Denetim Alanı Üzerindeki Etkileri}

Denetim alanı, bir yöneticiye ya da bir üste rapor veren ast sayısını ifade etmektedir. BT'nin denetim alanına bilinen ilk etkisi, operasyonel düzeyde çalışan (veri giriş operatörleri, ödünç verme bankosundaki görevliler gibi) işgören sayısında yarattığı azalmadır. Bundan dolayı işgören sayısındaki düşüşe koşut olarak, denetim alanının da daralacağı varsayımı ileri sürülebilir (Öğüt, 2003, s. 76).

Bu konudaki bir başka varsayım da, örgütlerde daha etkili olma gereksinimi ve BT olanaklarından yararlanarak bilgiye evrensel bir kapı açma isteği, bilgi-belge merkezlerindeki geleneksel piramit biçimli yönetim yapısını yataylaştırmakta, denetim alanını genişletmekte ve işgören rollerini yeterlik ve uzmanlığa dayalı bir biçimde geliştirip, kaynaşmasına olanak tanımaktadır (Reynolds, 1986, s. 31).

\section{Yönetim Basamakları Üzerine Etkileri}

BT'yi itici bir güç haline getiren post-modern bakış açısı; bilgi-belge merkezlerinde, bir taraftan yerelleşmeye doğru gidişi hızlandırmış, diğer taraftan da BT aracılığıyla karar mekanizmalarının alt basamaklara doğru kaydııımasına neden olmuştur. BT, yöneticilere yüksek kalitedeki yararlı bilgiyi zamanında sunduğu için, geleneksel organizasyonlardaki katı basamaksal yapılar gittikçe daha organik ve basık (flat) yapılara dönüşmektedir (Stueart ve Moran, 1998, s. 151). Örgütlerdeki basamaksal yapının ortadan kalkarak daha düz ve yalın hale gelmesinin nedenleri arasında bilgisayarların, işgücü yerine ikame edilmesi sonucu denetleme ve yönetme işlevleri için yeni bir örgütsel düzey oluşturarak yetki devretmeye gereksinim kalmaması sayılabilir (Ögüt, 2003, s. 76).

Bu bağlamda bir başka yaklaşım da BT'nin orta kademe yönetime yapmış olduğu etkiler üzerinedir. Bu konuda iki farklı görüşten söz edilmektedir. İlk görüş, orta kademe yönetim görevlerinin azalacağını ifade ederken, ikinci görüş ise birincinin aksine, BT ile orta kademe görevlerinin artacağı hususundadır (Ülgen, 1990, s. 218). Orta kademe yönetim hakkındaki görüşler çeşitlilik göstermesine rağmen, yazarların birleştiği ortak nokta "örgütlerde BT kullanımının yaygınlaşması, tüm örgüt çalışanlarını etkilediği gibi orta düzey yöneticileri de etkilediğidir”. Günümüz modern yönetim yaklaşımlarına bakıldığı zaman bu konu, örgütün en alt kademesi ile en üst kademesi arasındaki mesafenin kısaltıması ve aradaki kademe sayısının azaltılmasını anlatan "kademe azaltma (delayering)" kavramıyla ele alınmak- 
ta ve çağdaş örgütlerde aynı veya farklı anlamlarda kullanılmaktadır (Kurulgan, 2004, s. 193).

\section{Hizmet Birimlerinin Performansı Üzerindeki Etkileri}

BT'nin hizmet birimlerinin performansını etkilemesi "yönetim bilgi sistemi" aracılığıyla gerçekleşmektedir. Yönetim faaliyetlerinde yöneticinin doğru kararlar alabilmesi ve etkin bir değerlendirme yapması, kendisine iletilen bilginin doğru, anlaşılır ve tam olmasıyla ilişkilidir (Bayrak, 2003, s. 172).

2004 yılında, Kurulgan tarafından yapılan "Bilgi teknolojisinin üniversite kütüphanelerinde yönetim işlevleri üzerine etkileri ve Türkiye'deki uygulamaya ilişkin bir araştırma" başlıklı doktora tez çalışmasında, Türkiye'deki 75 üniversite kütüphanesinden 7'sinin işlevlerini yerine getirirken BT olanaklarından yararlanmadıkları, geriye kalan 68 üniversite kütüphanesinden, anket sorularını yanıtlayan, 49 kütüphanenin "yönetim işlevleri"nde BT olanakları (yönetim bilgi sistemi) kullanıldığı tespiti yapılmaktadır. Araştırma bulguları BT'nin yönetsel performansı artırdığını göstermektedir (Bkz. Tablo 1); (Kurulgan, 2004, s. 222-223).

\section{Tablo 1: BT'nin Yönetsel Faaliyetlere Katkılarına Göre Kütüphanelerin Dağılımı}

\begin{tabular}{|l|c|c|}
\hline BT'nin Kütüphane Yönetim Faaliyetlerine Katkıları & $\begin{array}{c}\text { Kütüphane } \\
\text { Sayısı }\end{array}$ & $\begin{array}{c}\text { Yüzde } \\
\text { (\%) }\end{array}$ \\
\hline $\begin{array}{l}\text { Elde edilen bilgiler yöneticilerin davranış ve kararlarını } \\
\text { kolaylaştırmıştır. }\end{array}$ & 45 & 91.8 \\
\hline Planlama, karar verme ve hizmet yöntemlerini geliştirmiştir. & 44 & 89.8 \\
\hline $\begin{array}{l}\text { Yönetimde modernleşme ve modern yönetim tekniklerinin } \\
\text { geliştirilmesini sağlamıştır. }\end{array}$ & 36 & 73.5 \\
\hline $\begin{array}{l}\text { Daha belirgin ve düzenli bir yönetim anlayışının } \\
\text { yerleşmesini sağlamıştır. }\end{array}$ & 36 & 73.5 \\
\hline
\end{tabular}

\section{Liderlik Üzerine Etkileri}

BT'nin bilgi-belge merkezlerinde kullanılmaya başlamasıyla birlikte kütüphanecilik (bilgi-belge yönetimi) literatüründe iki yönlü bakış açısı geliştirilmeye başlanmıştır. Bunlardan birincisi BT'nin etkilerini yönetmek; diğeri ise gelecek için kütüphaneleri biçimlendirmede BT'den nasıl yararlanılacağını planlamaktır (Lovry, 1993, s. 239). Yönetim alanında yaşanan bu tür dönüşümler, hiç şüphesiz liderler tarafından uygulanıp geliştirilmektedir. 
Bilgi çağı ile birlikte yönetim düşünce ve uygulamalarında yaşanan dönüşümler, yöneticilerin, bütün sorun ve sorulara uygun çözüm ve yanıtları bilen yöneticilik anlayışından kurtularak; görevlerini katılımcılık ve yetki devri ile astlarına devretmesini, kendilerinin de vizyon belirlemek, yeni ufuklar açmak, değişim ve yenilenmeyi gerçekleştirmek, yeni eğilimler saptamak, astlarına çalışma heyecanı ve güdüleme sağlamak suretiyle dönüşümcü lider olarak farklılaşma yaratma çalışmalarını gerekli kılmaktadır (Marcum, 2003; Bingöl, Naktiyok ve İşcan, 2003, ss. 492-494; Koçel, 2003, s. 605).

\section{Bilgi Teknolojisinin Paydaşlar (Stakeholders) Açısından Getirdiği Yenilikler}

Örgütteki paydaş, örgütsel amaçların başarılmasını etkileyen ve/veya başarısından etkilenen bir grup veya kişiyi ifade etmektedir (Özalp ve Tonus, 2003, s. 161). Bu paydaşlar; işveren, uzmanlar, satıcılar, rakipler ve gerçekte müşteriler de (kullanıcılar) dahil olmak üzere, değer zinciri içerisinde yer alan herhangi biri veya birilerinin oluşturduğu insan grupları olabilmektedir.

BT'nin ilkeleri, bilgi-belge merkezleri de dahil olmak üzere iş alanlarını paydaş yönetim ilişkisinde daha duyarlı olmaya zorlamaktadır. Bir başka deyişle; kütüphaneciler, işverenleri ve ilgili ünitelerce belirlenen stratejik yönlere karşı kurumun eşgüdümünü sağlaması yönünde gittikçe artan bir baskının etkisine girmektedir. Bundan dolayı kütüphaneciler işverenlerine bilgi-belge merkezlerinin değerlerini delillerle göstermeli ve merkezlere sağlanan yatırımların hakkını verebilmeleri gerekmektedir. Benzer biçimde, kütüphaneciler (bilgi-belge uzmanları), hem kurum içinde hem de ilgili birimlerdeki paydaşlarla stratejik bir ortaklık kurarak, merkezlerin yeterlilik ve etkililiği konusunda daha pozitif bir etki oluşturabilmelidir. Bilgi toplumunda "insan unsuru öncelikli bir varlıktır" düşüncesinden hareketle paydaşlar, örgüt misyonunu destekleyecek birçok yönde harekete geçirilmeli ve stratejik ortaklar belirlenmelidir (Hooper, 2001, s. 75).

\section{Sonuç ve Öneriler}

Son yıllarda BT'de yaşanan baş döndürücü gelişmeler, bilgi-belge merkezlerinde teknoloji kullanımını artırarak yapısal ve yönetsel dönüşümlere neden olmaktadır. Bu bağlamda, bilgi-belge merkezleri yapısal ve yönetsel açılardan "bilgi kayıt ortamları, bina, iş akışı, işgören ve yönetici, işbirliği, standartlaşma, hizmetler, kütüphane/bilgi-belge merkezi kavramı, örgüt kültürü, yönetim ve organizasyon yapısı, paydaşlar" gibi konularda yeniden yapılanma sürecine girmişlerdir. Bu süreç aşağıda kısaca özetlenmektedir:

> BT'nin bilgi-belge merkezlerinde yaygın olarak kullanıldığı 1990'ı yıllardan itibaren, bilgi kayıt ortamları kağıda dayalı olmaktan çıkarak elektronik formlara dönüşmektedir. 
> BT kullanımının yaygınlaşmasıyla, coğrafik yerleşim bölgeleri ve uzaklıklar bilgi ve belgeye erişim için bir engel olmaktan çıkmış, geleneksel bilgi-belge merkezlerinde yaşanan belgelerin depolanma sorunlarına çözüm olanağı getirmiştir.

> Bilgi-belge merkezlerindeki rutin işlerin tekrarını en aza indirerek geleneksel iş akışını değiştirmiş, belgenin sağlanmasından kullanıcıya ulaştırılmasına kadar olan süreç daha etkin kılınmıştır.

> İşgören ve yöneticilerin geleneksel rolleri değişmiş ve kendilerini yenilemelerine olanak sağlanmışır. Bilgisayarların yardımıyla rutin işleri en aza inen işgören, merkezin işleyişi hakkında daha fazla bilgi sahibi olmakta ve yaptığı işlerin daha etkin bir biçimde gerçekleştirilmesi konusunda fikir üretebilmektedir. Yönetici de, bilgisayara dayalı yönetim bilgi sistemleri aracılığıyla elde ettiği özet bilgiler sayesinde merkez hakkında daha etkin kararlar alabilmekte ve yapacağı planlarda daha uzgörülü olabilmektedir.

> Bilgi-belge yönetiminin çekirdeğini oluşturan işbirliği, standartlaşma ve kaynak paylaşımı konusundaki çalışmalar, bilgi ve iletişim teknolojileri sayesinde, büyük bir hız ve kullanım kolaylığına kavuşmuştur.

> Zamanın artık para anlamına geldiği günümüzde kullanıcının, gereksinim duyduğu bilgilere anında ve doğru bir biçimde ulaşması sağlanmıştır.

> Bilgisayar ve iletişim teknolojilerinde yaşanan dönüşümler, bilginin dağıtımı ve erişimindeki geleneksel yapıyı değiştirerek makalede tartışılan "elektronik kütüphane/bilgi-belge merkezi" kavramının doğmasına neden olmuştur.

> Sürekli yeni teknolojiler keşfetme ve üretme uğraşı, bilgi-belge merkezlerinin kültürel yapısında değişim ve uyum sürecine girmesine neden olmuştur. Böylece BT; bakış açıları, değerler, davranış kalıpları ve sosyal yaşama ilişkin yeni kurallar ile sosyal ve kültürel alanlarda büyük dönüşümlere imzasını atmıştır.

> BT, diğer örgütlerde olduğu gibi, bilgi-belge merkezlerinin de örgüt ve işleyiş yapısını değiştirerek; katııımc yönetim, dönüşümcü liderlik gibi çağdaş yönetim yaklaşımlarının yerleşmesine olanak tanımış ve sonuçta örgütsel performansı artırmıştır.

- Bilgisayara dayalı yönetim bilgi sistemleri; işveren, bilgi-belge uzmanları, tedarikçi firmalar (bilgi kaynağı ve/veya veri tabanı satıcıları), diğer bilgi-belge merkezleri ve kullanıcılar arasında etkin bir haberleşme sistemi yaratarak paydaşlarla örgüt arasındaki iletişimi güçlendirmiş̧ir. 
BT'nin bilgi ve belge yönetimi uzmanları, kullanıcılar ve bilgi-belge merkezlerine sağladığı üstünlüklerin yanı sıra, çeşitli kısıtlar ve engellerden de söz edilebilir. Örneğin, hangi amaçla kullanılacağı önceden ayrıntılı bir biçimde incelenmeden kurulmuş bilgisayar ve telekomünikasyon sistemi, sonradan kişiyi ve kurumu sistemin kapasitesiyle sınırlı kalma gibi bir sorunla karşı karşıya bırakabilmektedir. Ayrıca bilgi-belge merkezlerinde teknik alt yapı eksikliği, bağlantı sorunları, ürünlerdeki model değişimi gibi telekomünikasyon kısıtları yaşanabilmektedir. Gereklerini yerine getirmeden BT kullanımının fizyolojik ve/veya psikolojik sağlık sorunlarına ve performans düşüklüğüne neden olduğu herkes tarafından bilinmektedir.

BT'nin yaygınlaşması sonucu, kullanıcı ile ilgili sorunlar da ortaya çıkmaktadır. Örneğin, literatür taramasının BT ürünleri ile yapıldığı bir bilgibelge merkezinde, geleneksel danışma hizmetine göre olumsuz olan yön, kullanıcı ile kurulan yüz yüze ilişkileri gereksiz kılması nedeniyle insan ilişkilerinin giderek zayıflaması gerçeğidir. Bundan dolayı bilgi-belge yönetimi mesleğinin en önemli yönlerinden biri olan insan ilişkileri, otomasyonla yok olmakta veya en aza inmektedir.

Ayrıca bilgi-belge merkezlerinde BT kullanımı için donanım ve yazııım alımları, kurumlara büyük oranda maddi yük getirmektedir. Illk yatııım sonrasında mevcut sistemlerin geliştirilmesi, güncelleştirilmesi, güvenlik açıklarının kapatılması ve bakım masrafları da devam eden yıllarda önemini korumaktadır.

BT kullanımında yaşanan bir başka sorun da yasaların inlal edilmesidir. Hırsızık, sabotaj ve vandalizm gibi çeşitli başlıklar altında incelenebilen bilişim suçları alanında bilgi-belge merkezlerini en çok ilgilendiren, eser sahiplerinin fikrî mülkiyet haklarının çiğnenmesi sorunudur (Kurbanoğlu, 1997, s. 95; Tuncer, 1986, ss. 11-12; Dikmen, 2001; Tonta, 2002).

21. yüzyılın simgesi olan $B T$, ulusların gelişmişliğinin göstergesi olarak kullanılmaya başlamıştır. Bilgiyi üreten, bilgiye ulaşan ve topluma yaymayı başarabilen ülkeler, yeni bilgi ve belgelerin üretilmesi için bilgi-belge merkezlerine gereken önemi ve kaynağı hazırlamaktadır. Sürdürülebilir kalkınma, insanı esas alarak bilgi toplumu olma yolunda ilerleyen ülkelerce gerçekleştirilebilecektir. Bu yönde olumlu adımların atılabilmesi ancak bilginin etkin, verimli ve yaygın olarak üretimi ve iletilmesiyle olanaklıdır. Sistem yaklaşımına göre bilgi-belge merkezleri, üst sistem olan devlet örgütünün birer alt sistemi konumundadır. Bu bağlamda, BT'nin bilgi-belge merkezlerinde etkin kullanımını sağlamak için ulusal ve örgütsel düzeyde alınması gereken önlemlere ilişkin öneriler aşağıda belirtilmektedir: 
Ulusal Düzeyde Alınması Gereken Önlemler

> BT alanında 2003 verilerine göre Avrupa Birliği-15 (AB-15)'te her yüz kişinin 79'u, Türkiye'de her yüz kişinin 39'u cep telefonu abonesidir. AB'de her yüz kişiye 54.4 sabit telefon hattı düşerken, Türkiye'de bu rakam 27.6'dır. Hane halkı İnternet kullanımı 2003 yılında AB-15'te $\% 45$, Türkiye'de ise; \%8 civarındadır (Aydın ve Köstepen, 2005, s. 16). Türkiye, telekomünikasyon ve bilişim alanlarında $A B$ standartlarına ulaşmak için, Türkiye-AB müzakereleri çerçevesinde, önemli kararlar almaktadır. Günümüzde $A B$ müktesebatına önemli ölçüde uyum sağlanmıştır. Ancak ası önemli olan bu mevzuatın etkin bir biçimde uygulanması ile telekomünikasyon hizmetlerinin rekabetçi bir yapı içinde ucuza, kaliteli ve yaygın olarak sunulmasını sağlamak; böylece serbest bir ortamda meydana gelebilecek haksız rekabet ve tekelci yapılardan kaynaklanabilecek olumsuz sonuçları bu düzenlemeler kapsamında giderilmektedir (Prokop, 2002, s. 100).

> Bilgiye erişimdeki güçlükleri ortadan kaldırmak için gerekli BT donanımının üretimi özendirilerek ulusal alt yapı oluşturulmalıdır. Bu sayede İnternet erişimi daha ucuz hale gelebilecek ve bilgiye ulaşım yaygınlaşabilecektir.

> Ülkede bilgisayar okur-yazarlığı destek kampanyalarına önem verilmelidir. Örneğin, örgün eğitim boyutunda, ilköğretim okullarının öğretim programına bilgisayar kullanımı ile ilgili daha fazla ders konularak, yaygın eğitim boyutunda ise, Türkiye Bilişim Derneği'nin yürüttüğü Avrupa Bilgisayar Yetkinlik Sertifikası gibi eğitim programları parasal açıdan desteklenerek bilgisayar okur-yazar sayısı artırılabilir.

\section{Örgütsel Düzeyde Alınması Gereken Önlemler}

> Bilgi-belge merkezlerinde yazılım ve donanımla ilgili (örneğin, hangi amaçla kullanılacağı önceden ayrıntılı bir biçimde incelenmeden kurulmuş bilgisayar ve telekomünikasyon sistemi gibi) sorunların yaşanmaması için, kurulacak yazılım ve donanımın merkezin amaçlarına, dermesinin büyüklüğüne, kullanıcı ve işgören gereksinimlerinin karşılanmasına uygun olması gerekmektedir.

> Bilgi-belge merkezi yöneticileri, teknik işlevlerde ve yönetsel faaliyetlerde gelişmiş BT olanaklarından yararlanmak suretiyle, merkezin bağlı bulunduğu kurum/kuruluşun üst düzey yöneticilerine çeşitli önerilerden oluşan raporlar sunabilirler. Bu raporlar, yapılan maliyet ve etkinlik analizi sonucu elde edilen bilgiler ışığında, merkeze satın alınabilecek en uygun otomasyon sisteminin belirlenmesi biçi- 
minde olabileceği gibi, toplam maliyetleri düşürmek açısından, bağlı bulunduğu kurum/kuruluşun bünyesindeki bilgi işlem birimlerindeki uzmanlardan yardım alarak kendi otomasyon sistemlerini oluşturma şeklinde de hazırlanabilir.

$>$ Bilgi-belge merkezinin yönetici ve işgörenleri, BT boyutundaki eğitim programlarına tabi tutularak, gereksiz kaynak kullanımı ve olası örgütsel çatışmalar en aza indirilebilir. Bu nedenle, bilgi-belge merkezleri ve varsa bunlara bağlı şube birimleri personelinin hizmet-içi eğitim programlarına katılmaları önerilebilir.

- Uzman personel tarafından, merkez kullanıcılarına yönelik "BT Destekli Kullanıcı Eğitimi Programı" düzenlenebilir.

> BT kullanımı sonucu ortaya çıkan yasal sorunlar yine teknoloji desteğiyle çözülebilmektedir. Örneğin, elektronik ortamdaki eserlerin telif haklarını korumak için sayısal filigran gibi teknolojik çözümler üretilmeye, telif hakları elektronik telif hakları yönetim sistemi aracılığıyla izlenmeye çalışılabilir. Alınan bu tür önlemler bir taraftan yasal olmayan kullanımları engellerken, diğer taraftan kişisel ya da eğitim-öğretim amaçlı yasal kullanımları da engelleyebilmektedir. Bilgibelge merkezlerinin basılı eserleri kullanım ya da koruma amacıla kopyalanmalarına izin verilirken, sayısal bilgi kaynaklarını aynı amaçlarla kopyalamak sınırlandırılabilir.

> Merkezler, işlevlerini daha etkin kılmak için düzenli olarak "kullanıcıların ve merkez çalışanlarının beklentilerine yönelik araştırmalar" yapabilir ve elde edilen sonuçlara göre eylem planları oluşturabilirler.

> Bilgi-belge merkezlerinde çalışan uzman işgörenin, bilgi-belge yönetimi ve/veya yönetim-organizasyon gibi diğer disiplinlerde lisansüstü çalışması yapmaları özendirilebilir.

$>$ Bilindiği gibi BT, Türkiye'ye yabancı kökenli kaynaklardan gelmektedir. Itthal edilen teknolojiyi daha etkin biçimde kullanabilmek için merkez çalışanlarının yabancı dil düzeyleri çeşitli kurslarla geliştirilebilir.

\section{Kaynakça}

Alakuş, M. (2005). Kil tabletlerden sanal ortama: Bilginin düzenlenmesi ve pazarlanması. ÜNAK'05: Bilgi Hizmetlerinin Organizasyonu ve Pazarlanması, 22-24 Eylül 2005, İstanbul. İstanbul: Kadir Has Üniversitesi. 
Anameriç, H. ve Rukancı, F. (2004). Bilgi toplumu ve toplumun bilgilenmesinde kütüphanelerin rolü. S. Arslantekin ve F. Özdemirci (Yay. Haz.). Kütüphaneciliğin Destanı Uluslararası Sempozyumu Bildiriler 21-24 Ekim 2004 içinde (ss. 330-338). Ankara: Ankara Üniversitesi DTCF.

Aydın, S. ve Köstepen, C. (2005). AB tam üyeliğinin Türkiye vatandaşlarına sağlayacağı faydalar. İstanbul: İktisadi Kalkınma Vakfı.

Bahşişoğlu, H. K. ve Çömlekçi, K. (2002). Çevrim içi veri tabanının seçimi ve kullanımında kütüphanecilerin rolü. Akademik Bilişim '02: Seminer, 6-8 Şubat 2002, Konya. Konya: Selçuk Üniversitesi.

Bayrak, S. (2003). Bilişim teknolojilerinin yarattığı devrim: Toplumsal ve örgütsel etkileri. Bilgi Teknolojileri Kongresi-Il: Bildiriler 01-04 Mayıs 2003 içinde (ss. 170-172). Denizli: Pamukkale Üniversitesi.

Berberoğlu, G. (2002). Örgüt kültürü. İ. Özalp (ed.). Yönetim ve organizasyon içinde (ss. 249-266). Eskişehir: Anadolu Üniversitesi.

Bingöl, D., Naktiyok, A. ve İşcan, Ö. F. (2003). Dönüştürücü liderliğin örgütsel vatandaşlık davranışı üzerine etkisi. M. K. Çonkar (ed.). 11. Ulusal Yönetim ve Organizasyon Kongresi Bildiriler Kitabı 22-24 Mayıs 2003 içinde (ss. 491-508). Afyon: Afyon Kocatepe Üniversitesi.

Bozkurt, V. (2000). Enformasyon toplumu ve Türkiye (3. bs.). İstanbul: Sistem Yayıncilık.

Buckland, M. (2002). Redesigning library services: A manifesto. Berkeley: ALA. 9 Mayıs 2003 tarihinde http://sunsite.berkeley.edu/ Literature/Library/Redesigning/html.html adresinden erişildi.

Çömlekçi, K. (2005). Türkiye üniversiteleri toplu katalog projesi. 28 Eylül 2005 tarihinde http://www.unak.org.tr/unak05/sunum/pdf/kcomlekci.pdf adresinden erişildi.

Dikmen, Ç. ve Yahyagil, M. (2001). Illetişim sektöründe faaliyet gösteren bir şirketler grubunda bilişim teknolojileri uygulamalarına bağlı olarak yaşanan değişim sürecinin çalışanlar tarafından algılanması ile örgütün yapısal ve iklimsel özellikleri arasındaki ilişki. G. Dündar (ed.). 9. Ulusal Yönetim ve Organizasyon Kongresi Bildiriler 24-26 Mayıs 2001 içinde (ss. 885-905). İstanbul: İstanbul Üniversitesi.

Dikmen, S. (2001). Türkiye'de üniversite kütüphanelerinde otomasyon ve internet sistemlerinin geleceğe yönelik karşılaşabilecekleri sorunlar ve çözüm önerileri. Akademik Bilişim 2001. Samsun: Ondokuz Mayıs Üniversitesi. [Yazarın kendisinden 31 Aralık 2002 tarihinde e-posta yoluyla alınmıştır].

Hooper, T. (2001). Management issues for the virtual library. The Electronic Library, 19(2), 71-77. 
Koçel, T. (2003). İşletme yöneticiliği: Yönetim ve organizasyon, organizasyonlarda davranış, klasik-modern-çağdaş ve güncel yaklaşımlar (9. bs.). İstanbul: Beta Basım Yayım ve Dağıtım A. Ş.

Kohen, S. (2000). MyLibrary: Personalized electronic services in the Cornell University Library. D-Lib Magazine, April. 22 Mayıs 2002 tarihinde http://www.dlib.org/dlib/april00/mistlebauer/04mistlebauer.html adresinden erişildi.

Kurbanoğlu, S.S. (1997). Kütüphane otomasyonunun tarihsel gelişimine genel bir bakış. B. Yılmaz (Yay. Haz.). Kütüphanecilik Bölümü 25. Yıl'a Armağan içinde (ss. 93-99). Ankara: Hacettepe Üniversitesi Kütüphanecilik Bölümü.

Kurulgan, M. (2004). Bilgi teknolojisinin üniversite kütüphanelerinde yönetim işlevleri üzerine etkileri ve Türkiye'deki uygulamaya ilişkin bir araştırma. Yayımlanmamış doktora tezi, Anadolu Üniversitesi, Eskişehir.

Kurulgan, M. (2005). Bilgi teknolojisinin üniversite kütüphanelerindeki planlama ve örgütleme işlevleri üzerine etkileri ve Türkiye'deki uygulamaya ilişkin bir araştırma. Türk Kütüphaneciliği, 19(1), 41-55.

Küçük, M. E. (2004). "Diffuse libraries" ve MEB Eğitim Teknolojileri Müdürlüğü Bilgiye Erişim Merkezi (BEM). I. Ulusal Okul Kütüphanecileri Konferansı/ Bildiriler içinde (ss. 43-49). İstanbul: Oğlak Yayıncılık ve Reklamcılık Ltd. Şti.

Lakos, A. ve Gray, C. (2000). Personalized library portals as an organizational culture change agent. ITAL 19(4), 169-174. 10 MayIs 2005 tarihinde http://wotan.liu.edu/dois/data/Articles/jultmthpgy: 2000:v:19: i:4:p:169-174.html adresinden erişildi.

Lougee, W.P. (2003). Diffuse libraries. 142nd ARL Membership Meeting Proceedings 15 Mayıs 2003, Washington, DC. Washington, DC: Association of Research Libraries. 8 Kasım 2005 tarihinde http://create change.org/arl/proceedings/142/lougee.html adresinden erişildi.

Lougee, W. P. (2002). Diffuse libraries: Emergent roles for the research library in the Digital Age. USA: Council on Library and Information Resources. 10 Mart 2003 tarihinde http://www.clir.org/pubs/ reports/pub108/evolution.html adresinden erişildi.

Lovry, C. B. (1993). Managing technology: Perspectives and prospects for a new paradigm. Journal of Academic Librarianship, 19(4), 237-247.

Marchant, M. P. ve England, M. M. (1989). Changing management techniques as libraries automate. Library Trends, 37(4), 469-483. 
Marcum, J. W. (2003). Visions: the Academic library in 2012. D-Lib Magazine, 9(5). 8 Kasım 2005 tarihinde http://www.dlib.org/dlib/may03/ marcum/05marcum.html adresinden erişildi.

Öğüt, A. (2003). Bilgi çağında yönetim (2. bs.). Ankara: Nobel Yayın Dağıtım Ltd. Şti.

Özalp, İ. ve Tonus, Z. (2003). Paydaş teorisi (stakeholder theory) ve Freeman, Donaldson-Preston, Mitchell-Angle-Wood ve Arroll'un paydaş teorisine yaklaşımlarının incelenmesi. M.K. Çonkar (ed.). 11. Ulusal Yönetim ve Organizasyon Kongresi Bildiriler Kitabı 22-24 Mayıs 2003 içinde (ss. 161-176). Afyon: Afyon Kocatepe Üniversitesi.

Özel, N. (2005). Bibliyografik kayıtlar için işlevsel gerekler. ÜNAK'05: Bilgi Hizmetlerinin Organizasyonu ve Pazarlanması 22-24 Eylül 2005, İstanbul. İstanbul: Kadir Has Üniversitesi. 28 Eylül 2005 tarihinde http://www.unak.org.tr/unak05/sunum/pdf/nozel.pdf. adresinden erişildi.

Prokop, E. (2002). Avrupa Birliği'nin telekomünikasyon ve bilişim teknolojileri politikası ve Türkiye'nin uyumu. H. Cansevdi (ed.). İstanbul: İktisadi Kalkınma Vakfı.

Reynolds, B. A. (1986). Proactive management in public libraries: in California and the nation. G.B. McCabe ve B. Kreissman (ed.). Advances in Library Administration and Organization: A Research Annual (c. 6). Greenwich, CT.: JAI Press.

Sever, H. ve Tonta Y. (2005). Bilgi erişim sistemleri. Akademik Bilişim '05 Seminer 2-4 Şubat 2005, Gaziantep. Gazantep: Gaziantep Üniversitesi.

Steele, C. ve Guha M. (1999) Staffing the digital library in the 21st century. 6 Eylül 2002 tarihinde http://anulib.anu.edu.au/about/steele/ digital_library.html adresinden erişildi.

Stueart, R.D. ve Moran, B.B. (1998). Library and information center management. Englewood, Colorado: Libraries Unlimited, Inc.

Tonta, Y. (1998). Elektronik kütüphaneler. ULAKBiM Danışma Kurulları Ortak Toplantısı 18-19 Nisan 1998, Bolu. Bolu: Abant İzzet Baysal Üniversitesi.

Tonta, Y. (2002). Elektronik kaynaklarda yasal sorunlar. PULMAN-XT Türkiye Ulusal Toplantısı 16-19 Kasım 2002. Ankara: Milli Kütüphane. 7 Kasım 2005.tarihinde http://yunus.hacettepe.edu.tr/ tonta/yayinlar/pulman-telifhaklari.pdf adresinden erişildi.

Tuncer, N. (1986). Kütüphanede bilgisayar kullanımının getirdiği sorunlar. Türk Kütüphaneciler Derneği Bülteni, 6(3), 7-15. 
Turk.internet.com Haber Merkezi. (2004). Türkiye'de bilgi üretimi yılda \%30 artıyor-2. 3 Kasım 2005 tarihinde http://turk.internet.com/haber/ yazigoster.php3?yaziid=9057 adresinden erişildi.

Ülgen, H. (1990). İşletme yönetiminde bilgisayarlar (2. bs.). İstanbul: İstanbul Üniversitesi.

Yalvaç, M. (1994). Kütüphane hizmetlerinde bilgisayara geçiş ve sorunları. İstanbul: Mavibulut Yayınları.

Yontar, A. (1995). Kütüphane ve belge-bilgi merkezlerinde bilimsel yönetimin önemi. İstanbul: Türk Kütüphaneciler Derneği İstanbul Şubesi.

Yurdadoğ, B.U. (1997). Enformasyon Devrimi'nin getirdikleri, götüremedikleri. B. Yılmaz (Yay. Haz.). Kütüphanecilik Bölümü: 25. Yıl'a Armağan içinde (ss. 71-85). Ankara: Hacettepe Üniversitesi Kütüphanecilik Bölümü. 